\title{
Autologous bone graft harvested during implant site preparation: histological study
}

\author{
Mario Santagata ${ }^{1}$, Umberto Tozzi ${ }^{1}$, Rosario V. E. Prisco ${ }^{2}$, Gianpaolo Tartaro', \\ Salvatore D'Amato' ${ }^{1}$ \\ ${ }^{1}$ Multidisciplinary Department of Medical and Dental Specialties, Division of Oral and Maxillofacial Surgery, AOU - Second University \\ of Naples, Piazza Miraglia 2, 80138 Naples, Campania, Italy. \\ ${ }^{2}$ C.A.G.S. Prosthodontics, Private Practice, San Giorgio a Cremano, 80046 Naples, Campania, Italy.
}

Address for correspondence: Dr. Mario Santagata, Piazza Fuori Sant'Anna 17, 81031 Aversa, Caserta, Italy.

E-mail: mario.santagata@policliniconapoli.it

\begin{abstract}
Aim: The bone particles harvested during osteotomy could be used as autogenous bone graft materials to correct a bony defect prior to implant placement. Methods: A simple surgical procedure was described in which autogenous bone was harvested from the drills during the preparation of implant sites. Eleven samples were obtained from bone drilling during fixture installation in 11 patients (5 men and 6 women) with an average age of 57 years. These samples were subjected to histological preparation, in order to evaluate for the presence of viable osteoblasts. Results: Histological evaluation of the samples suggested that the viability of the bone tissue was maintained. Conclusion: The results show that this method of harvesting autogenous bone may be useful in situations where small amounts of bone are required.
\end{abstract}

Key words:

Bone graft, bone harvesting, oral implantology

\section{INTRODUCTION}

In our clinical practice, a bone graft is often necessary to correct a bony defect prior to implant placement. Autologous bone is considered to be the "gold standard" for bone grafting,,$^{[1-3]}$ as it does not produce adverse reactions and has optimal biocompatible remodeling patterns and osteoinductive capabilities. ${ }^{[4-6]}$ Grafting particulate bone is considered to be a better option than en bloc harvesting due to the former's capacity to adapt to the site of engraftment; it enables a larger quantity of harvested material to be grafted, with advantages in terms of long-term cell survival, although the latter is influenced both by the harvesting technique and the dimensions of the particles. ${ }^{.7]}$

The aim of this study was to assess the presence of viable

\begin{tabular}{|l|l|}
\hline \multicolumn{2}{|c|}{ Access this article online } \\
\hline Quick Response Code: & Website: \\
\hline & www.parjournal.net \\
\cline { 2 - 2 } & \\
\hline & Dol: \\
\hline
\end{tabular}

osteoblasts in bone tissue harvested with drills during implant site preparation.

\section{METHODS}

Clinical procedure and patient selection

A total of 11 patients ( 5 men and 6 women, aged between 35 and 75 years, with an average age of 57 years), in good general health condition, were included in this study. Patient selection criteria for this study were established so as to include patients with loss of one or more dental elements and with moderate alveolar atrophy diagnosed in preoperative X-ray examinations, including panoramic radiography. An Ethical Committee evaluated and accepted the guidelines of the study. All patients gave their informed consent to participate in the study.

\section{Surgical procedure}

All surgeries were performed under sterile conditions. Chlorhexidine $0.2 \%$ was used to rinse the oral cavity for 2 min prior to surgery. Local anesthesia consists of 1:200,000 mepivacaine-epinephrine was infiltrated into the mandibular/maxillary surgical site. An implant of adequate length was selected by radiographic examination, and a full thickness flap was designed. Implants were 
then placed following a modified drilling sequence to undersize the osteotomy and increase the insertion torque. The implant system's drills were of kind implant fixture with parallel shape. Drills set a low speed were used in succession, harvesting autogenous bone from the drills for later bone defect grafting. A precision initial drill allowed accurate positioning of the osteotomy within the palatal alveolar wall. Once the direction of drilling was established, the site was enlarged with a $2 \mathrm{~mm}$ pilot drill. Subsequent twist drills were used to widen the osteotomy following the manufacturer's instructions. The final drill however, was only utilized to a depth of approximately two-thirds of the implant length.

Implant site was prepared using a surgical motor (Implantmed, W and $\mathrm{H} \mathrm{GmbH}$, Burmoos, Austria) at a speed of $350 \mathrm{rpm}$ and a torque setting of $45 \mathrm{Ncm}$. A particulate bone graft was harvested from the drills, while the implant site was prepared without irrigation with saline solution [Figures 1 and 2].

Finally, internal implants with a laser microgrooved coronal design (Biohorizons, Birmingham, Ala) were placed. Implant placement was performed using a surgical motor (Implantmed, W and $\mathrm{H} \mathrm{GmbH}$, Burmoos, Austria) at a speed of $15 \mathrm{rpm}$ and a torque setting of $45 \mathrm{Ncm}$. In all cases, a ratchet wrench was used to fully seat the implants as the torque required exceeded the $45 \mathrm{Ncm}$ set on the motor. The harvested material was used to fill the bony defects. At that time, a small sample of the harvested material was also sent for histological analysis.

Following surgery, patients were instructed not to brush or irritate the surgical sites for 10 days, to irrigate their mouth with chlorhexidine $0.2 \% 3$ times a day for 1 week, and to maintain a soft diet for about 6 weeks. Analgesics (ibuprofen, $400 \mathrm{mg}$ ) and antibiotics (amoxicillin, $1,000 \mathrm{mg}, 3$ times daily) were prescribed to be taken for 1 week. Ten days after implant insertion, the sutures were removed.

\section{Histological analysis}

The samples harvested for histology at the time of implant installation were fixed for $24 \mathrm{~h}$ in a neutral formaldehyde solution of $10 \%$ Leica ASP $300 S^{\circledR}$ (Leica Biosystems Richmond, Inc. IL 60071) Tissue Processor. Subsequently, they were decalcified in a vial containing $10 \%$ ethylenediaminetetraacetic acid (EDTA) for 4 weeks. The EDTA solution was changed every week in order to remove the calcium from the bone fragments through chelation. After decalcification, the samples were embedded in paraffin, sliced with a microtome (Leica RM2125RT Microtome ${ }^{\circledR}$, Leica) and stained with hematoxylin and eosin in Leica Autostainer ST5020 ${ }^{\circledR}$ (Leica), after which they were ready for microscopic analysis.

\section{RESULTS}

Histological evaluation of the samples with an optical microscope showed that, even in a particulate state, the bone structure was well-preserved [Figures 3 and 4], containing a large number of osteocytes within the

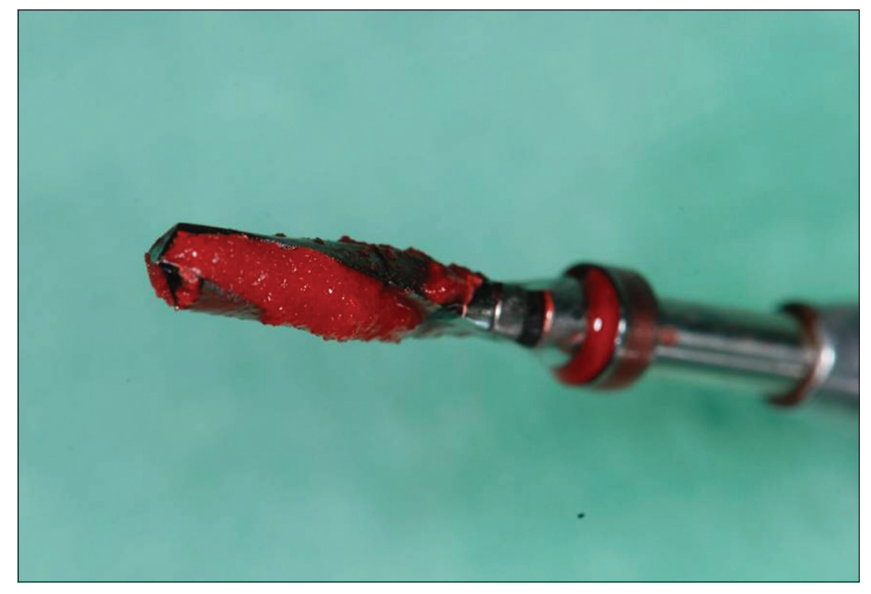

Figure 1: Particulate bone graft is harvested from the drill

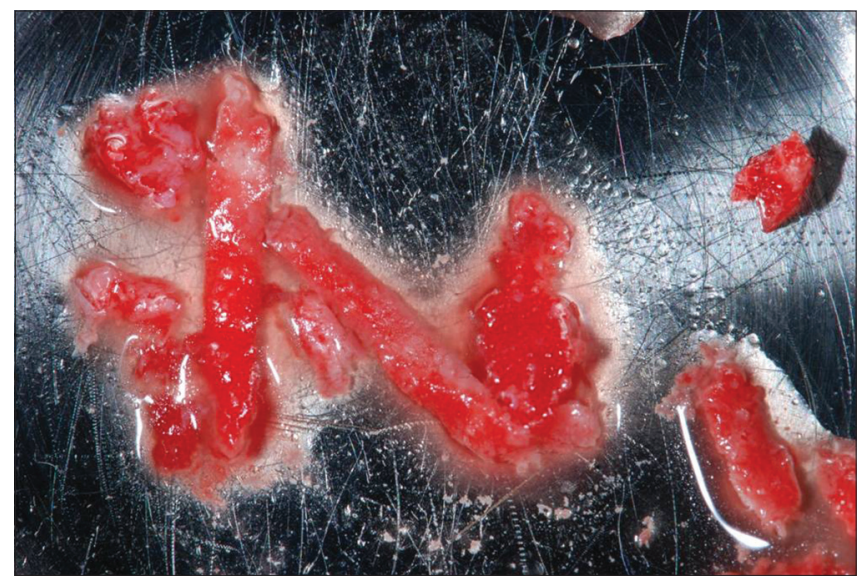

Figure 2: A harvested particulate autologous bone graft

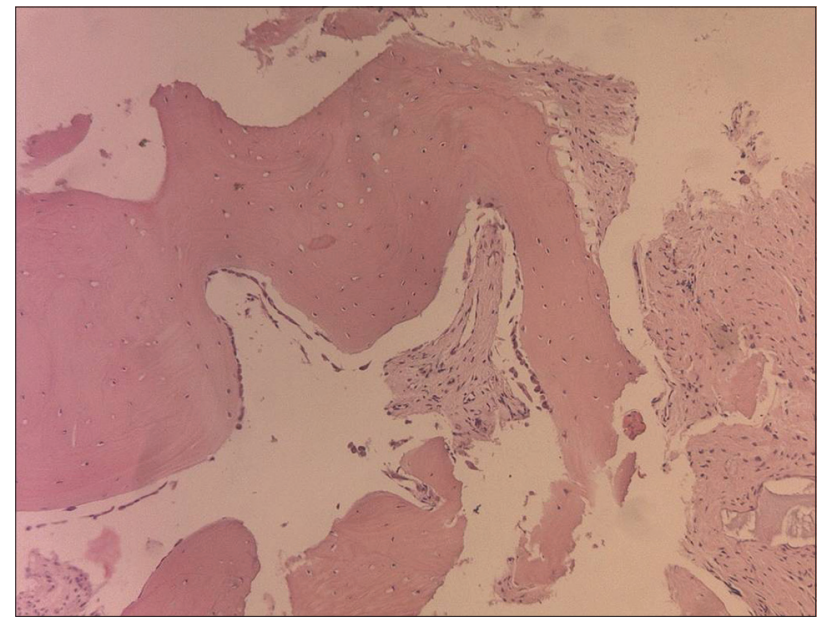

Figure 3: Panoramic view. Histological appearance of the bone harvested from the drills $(\mathrm{HE}, \times 10)$

calcified matrix and a large number of osteoblasts, expressing viable cells, and suggesting that the viability of the bone tissue was maintained and able to begin ostogenesis. A large number of osteocytes and osteoblasts were contained in all samples.

\section{DISCUSSION}

Bone particles harvested during implant site preparation consist of a mixture of cortical bone and cancellous bone, 


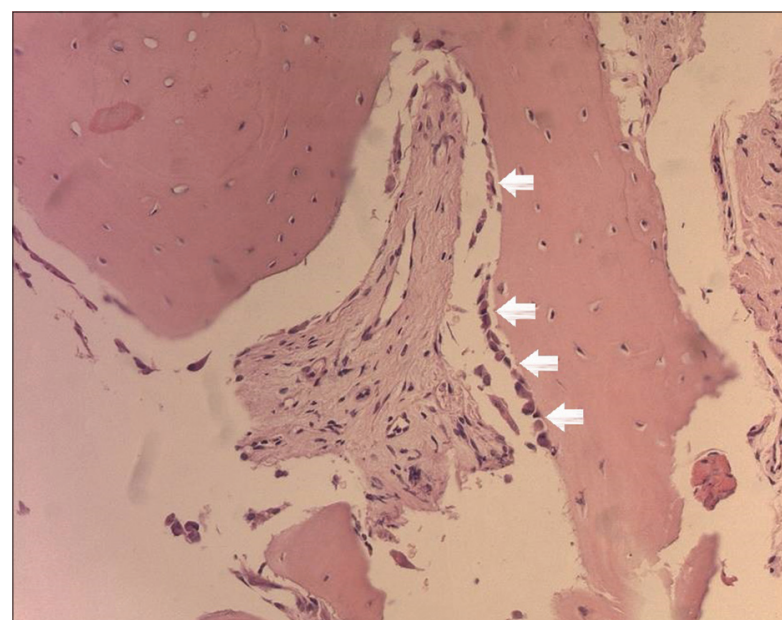

Figure 4: The picture shows continuous osteoblasts line (arrows) on mature bone $(\mathrm{HE}, \times 20)$

and have histologically well-preserved structures with a large number of osteocytes in a calcified matrix. ${ }^{[8]}$ In an animal study, Coradazzi et al. ${ }^{[9]}$ found that harvested bone resorbed more rapidly and showed higher osteoinductive potential than particulate bone in the early healing stages.

Particle size and available bone volume are important factors for graft material. In general, small particles are preferred secondary to more rapid resorption, greater surface area, and enhanced ostogenesis, ${ }^{[10-12]}$ but particles that are too small lack the space for the migration and proliferation of cells, vessels, and bone. A pore size of at least $100 \mu$ is necessary. Zaner and Yukna $^{[12]}$ recommended that an appropriate particle size would be $300-500 \mu$.

Grafting particulate bone is considered a better option than en bloc harvesting because of the former's capacity to adapt to the site of engraftment; it enables a larger quantity of harvested material to be grafted, with advantages in terms of long-term cell survival, although the latter aspect is influenced both by the harvesting technique and the dimensions of the particles. ${ }^{[7]}$

The drill was set at low speed as this has been shown to preserve viable osteocytes. ${ }^{[13,14]}$ For these reasons, an investigation was made on the methods of obtaining autogenous bone tissue by means of drills, and the possibility for preservation of cells with bone induction capacity was evaluated.

The use of bone harvested should be considered to be an extremely conservative technique, since it eliminates the need to obtain autogenous bone material from a second surgical site, which can be complex. ${ }^{[15]}$

There are no studies to date which have histologically evaluated the bone harvested during implant site preparation. From the results obtained it is concluded that the harvesting method described is capable of preserving cells with bone induction capacity, secondary to a large number of osteoblasts and the expression of viable cells. This suggests that the viability of the bone tissue is maintained and can begin osteogenesis. Another positive factor is the utilization of autogenous bone tissue of membranous and not of endocondral origin, a material known to be more efficient because it has lower reabsorption levels. ${ }^{[16]}$

The surgical technique described for the procurement of particulate intraoral autogenous bone material is simple, efficient and safe. The possibility of harvesting bone graft while the implant site is being prepared allows the procurement of the particulate bone without the disadvantages of donor site morbidity.

\section{ACKNOWLEDGMENTS}

The authors wish to thank Dr. Adolfo Apicella of the Anatomy and Histopathology Department "Luciano Armanni," Second University of Naples, Naples, Italy, for his valuable contribution to the present study.

\section{REFERENCES}

I. Jakse N, Seibert FJ, Lorenzoni M, Eskici A, Pertl C. A modified technique of harvesting tibial cancellous bone and its use for sinus grafting. Clin Oral Implants Res 200I;12:488-94.

2. Gamradt SC, Lieberman JR. Bone graft for revision hip arthroplasty: biology and future applications. Clin Orthop Relat Res 2003;(4I7): 183-94.

3. Mazock JB, Schow SR, Triplett RG. Proximal tibia bone harvest: review of technique, complications, and use in maxillofacial surgery. Int J Oral Maxillofac Implants 2004;19:586-93.

4. Matsuda M, Satoh Y, Ono K. Scanning electron microscopic and light microscopic observations on morphological changes of freeze-dried bone implantation in rats: comparison with fresh autogenous bone transplantation. Histol Histopathol 1992;7:393-403.

5. Hu ZM, Peel SA, Sandor GK, Clokie CM. The osteoinductive activity of bone morphogenetic protein (BMP) purified by repeated extracts of bovine bone. Growth Factors 2004;22:29-33.

6. Bünger $\mathrm{MH}$, Langdahl BL, Andersen T, Husted L, Lind M, Eriksen EF, Bünger CE. Semiquantitative mRNA measurements of osteoinductive growth factors in human iliac-crest bone: expression of LMP splice variants in human bone. Calcif Tissue Int 2003;73:446-54.

7. Peleg M, Garg AK, Misch CM, Mazor Z. Maxillary sinus and ridge augmentations using a surface-derived autogenous bone graft. J Oral Maxillofac Surg 2004;62:1535-44.

8. Blay A, Tunchel S, Sendyk WR. Viability of autogenous bone grafts obtained by using bone collectors: histological and microbiological study. Pesqui Odontol Bras 2003; 17:234-40.

9. Coradazzi LF, Garcia IR Jr, Manfrin TM. Evaluation of autogenous bone grafts, particulate or collected during osteotomy with implant burs: histologic and histomorphometric analysis in rabbits. Int J Oral Maxillofac Implants 2007;22:201-7.

10. Shapoff CA, Bowers GM, Levy B, Mellonig JT, Yukna RA. The effect of particle size on the osteogenic activity of composite grafts of allogeneic freeze-dried bone and autogenous marrow. J Periodontol 1980;51:625-30.

II. Pallesen L, Schou S, Aaboe M, Hjørting-Hansen E, Nattestad A, Melsen F. Influence of particle size of autogenous bone grafts on the early stages of bone regeneration: a histologic and stereologic study in rabbit calvarium. Int J Oral Maxillofac Implants 2002; 17:498-506.

12. Zaner DJ, Yukna RA. Particle size of periodontal bone grafting materials. J Periodontol 1984;55:406-9.

13. Rogers GF, Greene AK, Mulliken JB, Proctor MR, Ridgway EB. Exchange cranioplasty using autologous calvarial particulate bone graft effectively repairs large cranial defects. Plast Reconstr Surg 201 I;127:1631-42.

14. Beederman M, Alkureishi LW, Lam S, Warnke P, Reid RR. Exchange hybrid cranioplasty using particulate bone graft and demineralized bone matrix: the best of both worlds. J Craniofac Surg 2014;25:45 I-4. 
15. Al-Nawas B, Schiegnitz E. Augmentation procedures using bone substitute materials or autogenous bone-a systematic review and meta-analysis. Eur J Oral Implantol 2014;7:219-34.

16. Sindet-Pedersen S, Enemark $\mathrm{H}$. Reconstruction of alveolar clefts with mandibular or iliac crest bone grafts: a comparative study. J Oral Maxillofac Surg 1990;48:554-8.
How to cite this article: Santagata M, Tozzi U, Prisco RV, Tartaro G, D'Amato S. Autologous bone graft harvested during implant site preparation: histological study. Plast Aesthet Res 2014;1:94-7.

Source of Support: Nil, Conflict of Interest: None declared.

Received: 09-05-2014; Accepted: 21-07-2014 